\title{
IMPLEMENTASI AUGMENTED REALITY UNTUK IDENTIFIKASI LOGO DAN VIDEO SEBAGAI MEDIA INFORMASI MENGGUNAKAN METODE KLASIFIKASI NAIVE BAYESIAN
}

\author{
Astrid Novita Putri \\ Fakultas TIK \\ Universitas Semarang \\ Email: astrid@usm.ac.id \\ Siti Asmiatun \\ Fakultas TIK \\ Universitas Semarang \\ Email: siti.asmiatun@usm.ac.id
}

\begin{abstract}
ABSTRAK
Pada Universitas Semarang Fakultas Teknologi Informasi dan Komunikasi setiap tahun selalu mempunyai banyak kegiatan seperti kegiatan Seminar, Workshop, Pelatihan, Festifal, dsb. Kegiatankegiatan tersebut biasanya didokumentasikan dalam bentuk foto dan video. Sedangkan untuk dokumentasi publikasi kegiatan dalam bentuk media promosi maupun media informasi belum dilakukan, sehingga masyarakat umum yang kurang familiar tidak dapat mengetahui informasi dengan kegiatan yang ada. Memanfaatkan aplikasi smartphone yang berbasis android, blackberry, dan iphone dapat menggunakan salah satu teknologi augmented reality 3D yang berfungsi untuk mengidentifikasi informasi melalui logo Fakultas TIK dan menerapkannya pada berbagai media cetak atau elektronik. Sehingga dengan adanya perubahan cara promosi tersebut diharapkan dapat menarik minat perhatian masyarakat umum dan masyarakat umum untuk mengetahui informasi mengenai kegiatan di Universitas Semarang khususnya Fakultas Teknologi Informasi dan Komunikasi. Pada penelitian ini, akan membahas bagaimana mengklasifikasikan kegiatan-kegiatan tersebut menggunakan metode naive bayes menjadi dua kategori yaitu favorit atau tidak favorit. Berdasarkan data foto dan video kegiatan FTIK tahun 2017 yang telah diimplementasikan menggunakan tools Unity 3D menunjukkan bahwa penerapan Augmented Reality untuk identifikasi logo sebagai media informasi menggunakan metode klasifikasi naive bayes dapat diimplementasikan dengan baik. Diharapkan dengan adanya klasifikasi kegiatan dengan memanfaatkan teknologi augmented reality yang diimplementasikan menggunakan tools Unity 3D, informasi yang dihasilkan akan lebih informatif dan menarik perhatian masyarakat umum.
\end{abstract}

Kata kunci: augmented, reality, naive, bayesian, kegiatan.

\begin{abstract}
At Semarang University, Faculty of Information and Communication Technology always has many activities such as Seminar, Workshop, Training, Festifal, etc. These activities are usually done in photos and videos. While for documentation of the publication of activities in the form of media campaigns and media information has not been done, so that the less familiar public can not know information with existing activities. Utilizing smartphone applications based on android, blackberry, and iphone can use one of the 3D augmented reality technology that serves to identify information through the logo of the Faculty of ICT and apply it to various print or electronic media. So that with the changes in the way of promotion is expected to attract the attention of the general public and the general public to find out information about the activities at the University of Semarang, especially the Faculty of Information and Communication Technology. In this study, will discuss how to classify these activities using naive bayesian method into two categories: favorite or non favorite. Based on data photos and videos of FTIK activities in 2017 that have been implemented using Unity 3D tools shows that the application of Augmented Reality for logo identification as information media using naive bayesian classification method can be implemented well. Expected with the classification of activities by utilizing augmented realitytechnology implemented using Unity $3 D$ tools, the resulting information will be more informative and attract the attention of the general public.
\end{abstract}

Keywords: augmented, reality, naive, bayesian, activity. 


\section{PENDAHULUAN}

Perkembangan Teknologi Informasi dan Komunikasi saat ini sangat berkembang pesat dalam menyajikan suatu promosi, maupun media informasi pada setiap perusahaan maupun Universitas. Augmented reality merupakan salah satu teknologi terbaru yang dapat menjadi media promosi dan media informasi dengan memadukan kondisi rekayasa atau maya dengan kondisi nyata dalam lingkungan nyata yang di tampilkan secara virtual menggunakan smartphone baik android, blackberry, maupun iphone. Di Universitas Semarang khususnya Fakultas Teknologi Informasi dan Komunikasi mempunyai banyak kegiatan seperti kegiatan Seminar, Workshop, Pelatihan, Festifal, dsb yang diadakan setiap tahun. Setiap kegiatan akan didokumentasikan dalam bentuk foto dan video. Akan tetapi dokumentasi kegiatan dalam bentuk media promosi maupun media informasi masih sangat kurang, sehingga masyarakat umum yang kurang familiar tidak dapat mengetahui informasi dengan kegiatan yang ada.

Augmented reality adalah teknologi yang sangat tepat untuk solusi dari permasalahan tersebut. penerapan teknologi augmented reality adalah sebagai media informasi yang akan menampilkan informasi tertentu bagi para penggunanya. Karena dengan memanfaatkan teknologi augmented reality pada logo dari suatu model logo, dan video animation yang dapat di tampilkan secara virtual menggunakan mobile phone baik android, blackberry maupun iphone akan lebih mudah menarik minat masyarakat untuk mengetahui informasi yang terkandung dari tampilan 3D yang akan menampilkan gambaran umum tentang kegiatan di Universitas Semarang khususnya Fakultas Teknologi Informasi dan Komunikasi. Pada penelitian ini, akan membahas dari segi pengolahan data dan video dimana data foto dan video tersebut akan diklasifikasikan menjadi dua kategori yaitu favorit dan tidak favorit, sehingga mahasiswa dan masyarakat dapat mengetahui kegiatan apa sajakah yang ada di fakultas TIK yang paling favorit dan tidak favorit dengan harapan dari informasi tersebut dapat menarik perhatian mahasiswa dan masyarakat umum untuk mengenal lebih lanjut tentang seluk beluk FTIK.

Nä̈ve Bayes merupakan pengklasifikasian dengan metode probabilitas dan statistik yang dikemukakan oleh ilmuwan Inggris Thomas Bayes. Menurut Olson dan Delen (2008, p102) menjelaskan Nä̈ve bayes untuk setiap kelas keputusan, menghitung probabilitas dengan syarat bahwa kelas keputusan adalah benar, mengingat vektor informasi obyek.

Sedangkan menurut Han dan Kamber (2011, p351) Proses dari The Nä̈ve Bayesian classifier, atau Simple Bayesian Classifier, sebagai berikut: (Andriani, 2012)

a. Variable D menjadi pelatihan set tuple dan label yang terkait dengan kelas. Seperti biasa, setiap tuple diwakili oleh vektor atribut $\mathrm{n}$ dimensi, $\mathrm{X}=(\mathrm{x} 1, \mathrm{x} 2, \ldots, \mathrm{xn})$, ini menggambarkan pengukuran $\mathrm{n}$ dibuat pada tuple dari atribut $\mathrm{n}$, masing-masing, A1, A2, ..., An.

b. Misalkan ada kelas m, C1, C2, ..., Cm. Diberi sebuah tuple, X, classifier akan memprediksi X yang masuk kelompok memiliki probabilitas posterior tertinggi, kondisi-disebutkan pada $\mathrm{X}$. Artinya, classifier naive bayesian memprediksi bahwa X tuple milik kelas Ci jika dan hanya jika, di jelaskan pada rumus dibawah ini:

$P(C i \mid X)>P(C j \mid X)$ For $1 \leq j \leq m, j \neq i$

Keterangan :

$\mathrm{P}(\mathrm{Ci} \mid \mathrm{X})=$ Probabilitas hipotesis $\mathrm{Ci}$ jika diberikan fakta atau record $\mathrm{X}$ (Posterior probability)

$\mathrm{P}(\mathrm{X} \mid \mathrm{Ci})=$ Mencari nilai parameter yang memberi kemungkinan yang paling besar (likelihood)

$\mathrm{P}(\mathrm{Ci}) \quad=$ Prior probability dari $\mathrm{X}$ (Prior probability)

$\mathrm{P}(\mathrm{X}) \quad=$ Jumlah probability tuple yg muncul, Sumber: Han dan Kamber (2011, p351)

\section{METODOLOGI PENELITIAN}

Pada bagian ini akan membahas mengenai jenis data dan metode pengumpulan data yang di gunakan

\subsection{Jenis Data}

Jenis data yang digunakan dalam penelitian ini yaitu:

a. Data primer, yaitu data yang diperoleh secara langsung dari objek penelitian, sebagai berikut : Kegiatan yang ada di fakultas TIK, Jumlah peserta, kemudian ranking yang akan di dapatkan.

b. Data sekunder, yaitu data yang diperoleh dari literature, buku referensi, maupun browsing internet. 


\subsection{Metode Pengumpulan Data}

Pengumpulan data yang dilakukan dalam penelitian ini adalah:

a. Observasi dan Wawancara : Pengumpulan data melalui pengamatan dan wawancara secara langsung dengan Ketua Program Studi Teknik Informatika, Sistem Informasi, dan Ilmu Komunikasi mengenai kegiatan apa sajakah yang ada di dalamnya dan menganalisa kriteria yang di gunakan dari jenis kegiatan, tanggal kegiatan, hasil kegiatan, dan ranking yang di dapat dari hasil klasifikasi jumlah peserta.

b. Studi Pustaka : Mengumpulkan literatur pendukung penelitian, baik dari buku referensi ataupun browsing dari internet.

\section{HASIL DAN PEMBAHASAN}

\subsection{Penentuan Kriteria}

Berikut ini adalah kriteria dalam menentukan hasil berdasarkan ranking menggunakan metode klasifikasi :

a. Progdi : Teknik Informatika, Sistem Informasi, Ilmu Komunikasi.

b. Jenis Kegiatan : Kuliah Umum, Workshop, Pelatihan, Kegiatan Akademik, Kegiatan Ilmiah.

c. Hasil Kegiatan (Berdasarkan Peserta) : Memuaskan, Cukup (Di dapatkan dari jumlah peserta kegatan)

d. Ranking : Favorit, Tidak Favorit.

\subsection{Dataset}

Berikut ini adalah tabel tranning kegiatan di Fakultas TIK di bawah ini pada tabel 2 mengenai Tranning Kegiatan Fakultas TIK:

Tabel 1. Tabel tranning kegiatan fakultas TIK [18]

\begin{tabular}{|c|c|c|c|c|}
\hline No & $\begin{array}{l}\text { Program } \\
\text { Studi }\end{array}$ & Jenis Kegiatan & Hasil Kegiatan & Ranking \\
\hline 1. & $\begin{array}{c}\text { Teknik } \\
\text { Informatika }\end{array}$ & $\begin{array}{c}\text { Workshop Instal U-Buntu Realase } \\
\text { Party } 11.04\end{array}$ & Memuaskan & Favorit \\
\hline 2. & $\begin{array}{c}\text { Teknik } \\
\text { Informatika }\end{array}$ & Workshop Framework PHP & Memuaskan & Favorit \\
\hline 3. & $\begin{array}{c}\text { Teknik } \\
\text { Informatika }\end{array}$ & Workshop Linux & Cukup & $\begin{array}{l}\text { Tidak } \\
\text { Favorit }\end{array}$ \\
\hline 4. & $\begin{array}{c}\text { Teknik } \\
\text { Informatika }\end{array}$ & Workshop Sistem Sensor & Memuaskan & Favorit \\
\hline 5. & $\begin{array}{c}\text { Sistem } \\
\text { Informasi }\end{array}$ & Workshop Website & Cukup & $\begin{array}{l}\text { Tidak } \\
\text { Favorit }\end{array}$ \\
\hline 6. & $\begin{array}{c}\text { Sistem } \\
\text { Informasi }\end{array}$ & Festifal IT Fest & Memuaskan & Favorit \\
\hline 7. & $\begin{array}{c}\text { Sistem } \\
\text { Informasi }\end{array}$ & Workhsop Mikrotik & Cukup & $\begin{array}{l}\text { Tidak } \\
\text { Favorit }\end{array}$ \\
\hline 8. & $\begin{array}{c}\text { Ilmu } \\
\text { Komunikasi }\end{array}$ & Pelatihan Lab. TV & Cukup & $\begin{array}{c}\text { Tidak } \\
\text { Favorit }\end{array}$ \\
\hline 9. & $\begin{array}{c}\text { Teknik } \\
\text { Informatika }\end{array}$ & $\begin{array}{c}\text { Workshop Instal U-Buntu Realse } \\
\text { Party }\end{array}$ & Memuaskan & Favorit \\
\hline 10. & $\begin{array}{c}\text { Teknik } \\
\text { Informatika }\end{array}$ & Workshop Framework PHP & Memuaskan & Favorit \\
\hline 11. & $\begin{array}{c}\text { Teknik } \\
\text { Informatika }\end{array}$ & Workshop Linux & Memuaskan & Favorit \\
\hline 12. & $\begin{array}{c}\text { Teknik } \\
\text { Informatika }\end{array}$ & Workshop Sistem Sensor & Memuaskan & Favorit \\
\hline 13 & $\begin{array}{c}\text { Teknik } \\
\text { Informatika }\end{array}$ & Workshop Website & Cukup & $?$ \\
\hline
\end{tabular}




\subsection{Implementasi Klasifikasi Naive Bayesian Pada Unity 3D}

Berikut ini adalah pengolahan data dengan menggunakan naive bayes pada Unity $3 D$ pada gambar 2:

a. Use Case Diagram

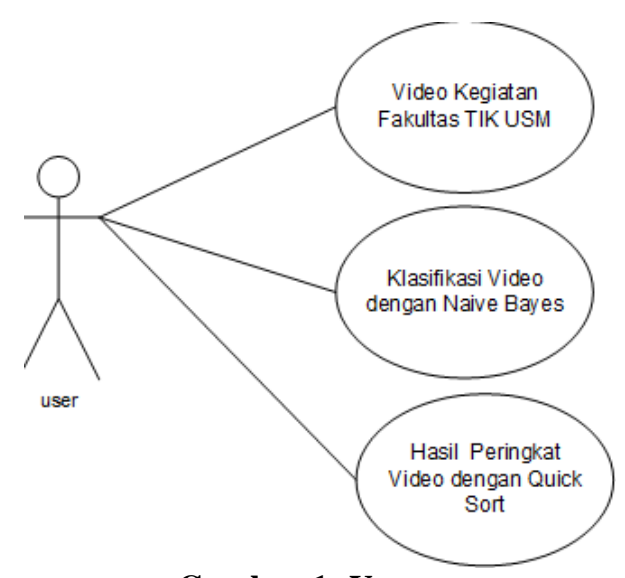

Gambar 1. Usecase

Dari gambar 1. usecase diatas merupakan gambaran dari alur sistem yang akan diimplementasikan menggunakan Unity 3D. Ada beberapa aktifitas yang dapat diakses oleh user atau pengguna yaitu menscan gambar logo ftik, menampilkan dan memilih AR pada semua kegitaan FTIK, menampilkan ranking, dan mengupload video kegiatan dan kriteria.

b. Tampilan hasil implementasi menggukan Unity 3D

Dibawah ini merupakan tampilan gambar dari hasil implementasi menggunakan tools Unity 3D. Digambar tersebut terdapat pilihan menu untuk melihat video kegiatan di Fakultas TIK USM. Kemudian terdapat pilihan menu untuk menampilkan peringkat kegiatan di Fakultas TIK USM dengan metode Naive bayes pada gambar 2 .

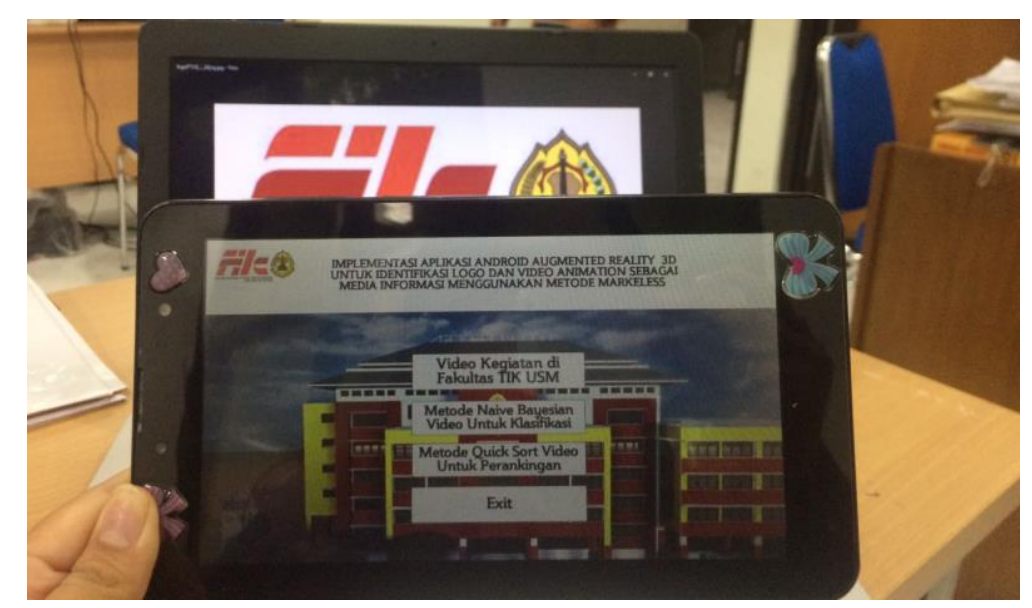

Gambar 2. Tampilan Scan Menu Utama Augmented Reality

Untuk gambar 3 dibawah ini merupakan hasil tampilan dari pilihan menampilkan peringkat kegiatan Fakultas TIK USM menggunakan metode naive bayes . Dari Hasil tampilan terdapat beberapa kegiatan yang sudah diklasifikasikan menggunakan metode naive bayes menjadi kegiatan favorit atau tidak favorit. 


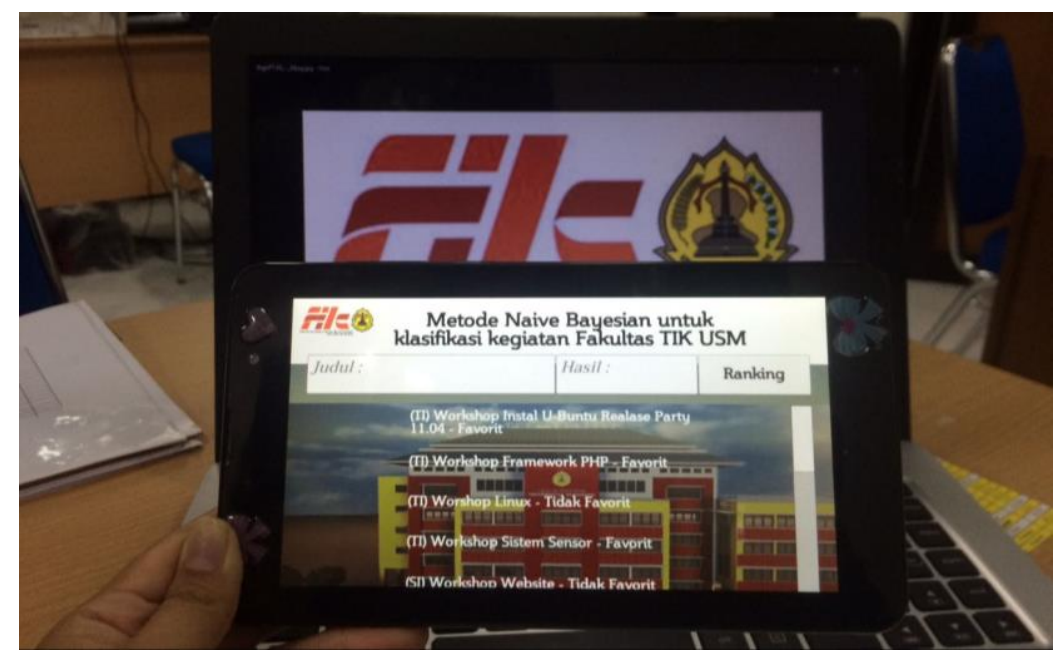

Gambar 3. Tampilan Scan Klasifikasi Kegiatan Menggunakan Naive Bayes

Dari Gambar 3 diatas merupakan hasil klasifikasi kegiatan diatas merupakan hasil dari perhitungan metode naive bayes dimana dari kategori favorit dan tidak favorit akan ditampilkan salah satu jika hasil nilainya $>=0$ tapi jika hasil nilainya $==0$ maka kategori tersebut tidak akan ditampilkan. Gambar 4 dibawah ini merupakan nilai akhir dari masing-masing kategori yang dihitung sesuai dengan metode naive bayes, hasil di tampilkan pada gambar 5.

\begin{tabular}{|c|c|c|c|c|c|}
\hline \multicolumn{2}{|c|}{ Project } & \multicolumn{4}{|l|}{ 目 Console } \\
\hline Clear & Collapse & Clear on Play & Error Pause & (1) 2 & $\Delta 0$ \\
\hline \multicolumn{5}{|c|}{$\begin{array}{l}\text { (1) Favorit }=0 \\
\text { UnityEngine. Debug:Log(Object) }\end{array}$} & 1 \\
\hline \multicolumn{5}{|c|}{$\begin{array}{l}\text { Tidak Favorit }=0.04166667 \\
\text { UnityEngine.Debug:Log(Object) }\end{array}$} & 1 \\
\hline
\end{tabular}

\section{Gambar 4. Hasil Nilai Inputan Naive bayes ian Nilainya Tidak Favorit}

c. Tampilan Script Function Naive bayes

Berikut ini adalah script function dengan nama "hitung.cs" yang di gunakan untuk menentukan hasil ranking dari klasifikasi kegiatan Fakultas TIK USM. Hasil dari perhitungan tersebut akan menampilkan klasifikasi kegiatan menjadi Favorit atau tidak favorit, kemudian untuk script di jelaskan pada gambar 5 .

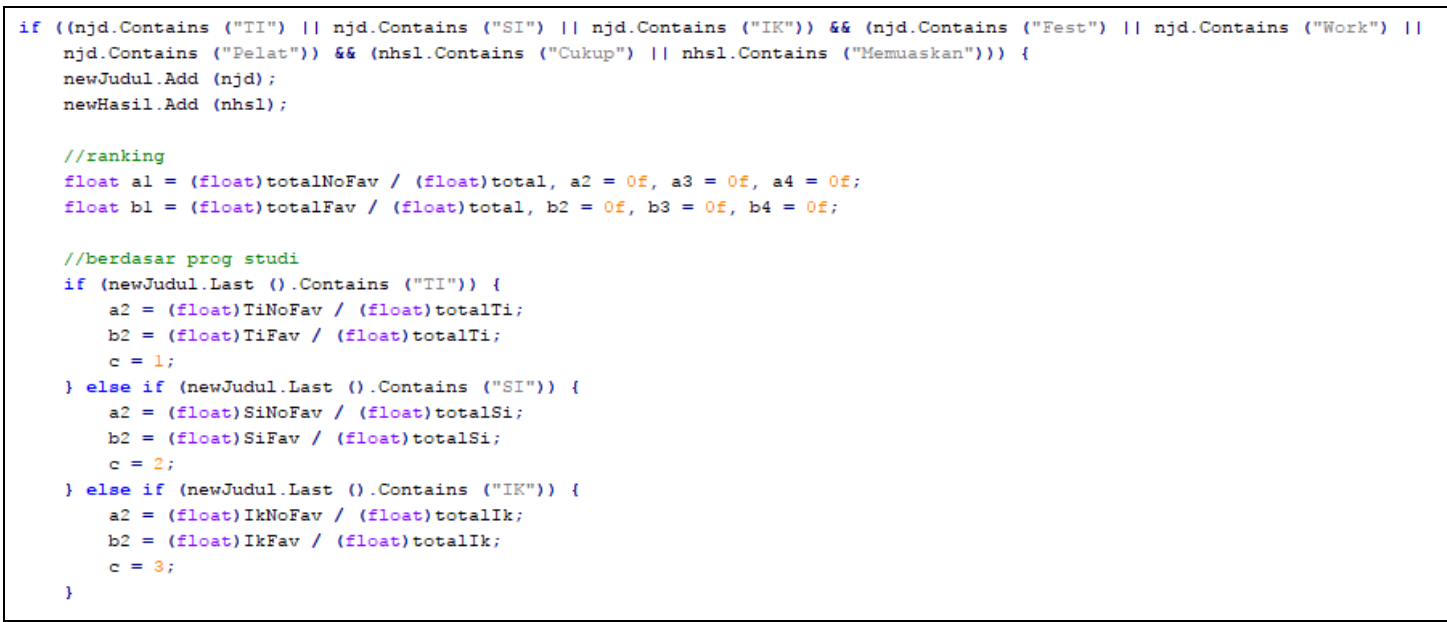

Gambar 5. Tampilan Script Function Naive bayes

\section{KESIMPULAN}

Dari penelitian ini dapat diambil kesimpulan bahwa berdasarkan data foto dan video kegiatan FTIK tahun 2017 yang telah diimplementasikan menggunakan tools Unity 3D menunjukkan bahwa penerapan 
Augmented Reality untuk identifikasi logo dan video sebagai media informasi menggunakan metode klasifikasi naive bayes ian dapat diimplementasikan dengan baik. Untuk saran penelitian selanjutnya dapat ditambahkan penilaian akurasi sehingga dapat menentukan tingkat ketepatan dari hasil penerapan metode. Dan untuk pengembangan penelitian yang akan datang dapat ditambahkan metode yang lain sebagai metode pembanding.

\section{UCAPAN TERIMA KASIH}

Peneliti ucapkan terimakasih kepada pihak Dikti dan Universitas Semarang yang telah membiayai penelitian dosen pemula ini.

\section{DAFTAR PUSTAKA}

[1] Zhang, Harry, and Shengli Sheng. "Learning weighted naive bayes with accurate ranking." Data Mining. ICDM'04. Fourth IEEE International Conference on. IEEE, 2004.

[2] Zhang, Harry, and Shengli Sheng. "Learning weighted naive bayes with accurate ranking." Data Mining, 2004. ICDM'04. Fourth IEEE International Conference on. IEEE, 2004.

[3] Wagner, Daniel, et al. "Real-time detection and tracking for augmented reality on mobile phones." IEEE transactions on visualization and computer graphics 16.3 (2010): 355-368.

[4] Coiras, E., et al. "Supervised target detection and classification by training on augmented reality data." IET Radar, Sonar \& Navigation 1.1 (2007): 83-90.

[5] Silva, R., et al. "Object recognition using bayesian networks for augmented reality applications." VII Symposium on Virtual Reality. 2004.

[6] Arsyad, Azhar.2011.’Media Pembelajaran.cetakan ke-15”.Jakarta:Rajawalli Pers".

[7] Andi Prastowo.2012."Metode Penelitian Kualitatif dalam Perspektif Rancangan Penelitian".

[8] McGraw, Ibiz Fernandez. 2002.”Macromedia Flash Animation \& Cartooning: A Creative Guide . Hill/Osborn", California

[9] Sobur, Alex. 2006. "Semiotika Komunikasi”. Bandung: PT Remaja Yosdakarya

[10] Degeng, I.N.S.1989.'Ilmu Pengajaran Taksonomi Variabel”.Jakarta : Depdikbud.

[11] Arief Sadiman. 2002. "Media Pembelajaran dan Proses Belajar Mengajar, Pengertian Pengembangan dan Pemanfaatannya",Jakarta: Raja Grafindo Persada.

[12] Gagne dan Briggs, Arsyad. 2002."Media Pembelajaran”Henderi. 2008. "Unified Modeling Language".

[13] Adi Purwoko Anggoro, Nur Wahyudi Eko. 2014."Pemanfaatan Teknologi Augmented Reality Untuk Marketing Pada Universitas Stikubank Semarang”. Dinamika Informatika Vol.6 No. 1, Maret 2014 ISSN 2085-3343.

[14] Tanggo Fery, dkk."Pembuatan Prototype Aplikasi Pengenalan logo Berbasis Android". Program Studi Teknik Informatika Fakultas Teknologi Industri Universitas Kristen Petra Surabaya.

[15] Juwono Felix, dkk.."Perancangan Portfolio PT Architecture Nine Dengan Pendekatan Media Visual Augmented Reality.” Program Studi Teknik Informatika Fakultas Teknologi Industri Universitas Kristen Petra Surabaya.

[16] Suryawinata, B. A. 2010. "Pemanfaatan augmented reality dalam memvisualisasikan produk perumahan melalui internet ". Comtech vol 1 no 2, 758-769.

[17] Xiang, Wang. "Analysis of the time complexity of quick sort algorithm." Information Management, Innovation Management and Industrial Engineering (ICIII), 2011 International Conference on. Vol. 1. IEEE, 2011.

[18] Tim Akreditas USM.2016."Evaluasi Diri Borang Akreditasi Program Studi Teknik Informatika Fakultas Teknologi Informasi dan KOmunikasi”. Universitas Semarang. 